\title{
The Latent Absolute Advantage Of The Comparative Advantage In Theories Of International Trade
}

\author{
Nguyen Thuong Lang, (Email: nguyenlang2020@yahoo.com), National Economics University - Hanoi, Vietnam
}

\begin{abstract}
The absolute advantage and comparative advantage are the basic concepts of the international economics. Up till now, the popular understanding about them is that absolute advantage is the special case of the comparative advantage. This view has been dominant in all books related to the field of international economics. However, the comparative advantage by nature is the absolute advantage. Generally, comparative advantage is only particular case of absolute advantage. In other words, comparative advantage has the latent absolute advantage. It is the opposite view of the traditional one on absolute and comparative advantage in the field of international trade theories and it constructs the content of this paper.
\end{abstract}

\section{DISCUSSION}

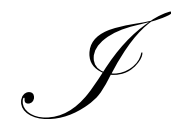

n the textbook "International Economics" D. Salvatore has written "Indeed, absolute advantage will be seen to be only a special case of the more general theory of comparative advantage" and the same view has been repeated in some other books related to the international economics. Up till now, this explanation has been kept unchanged in the economic literature in the field of international economics.

Historically, the definition on absolute advantage was initiated by A. Smith in his scientific work "The Wealth of Nations" published in 1776. According to his view the international trade would be occurred from the absolute difference on labor productivity among nations. If a Nation has higher productivity of labor in production of a product than that of the rest of the world, naturally, it has absolute advantage in this product. By this fact, such a Nation should specialize in production of this product and export it to the rest of the world and vice verse. The argument of A. Smith on absolute advantage based on the free trade among countries in the world. That means all trade transactions occurred as their nature by operation of the law of demand and supply in the market. By interaction among the market forces, trade must be beneficial for all related sides. If not, the lost sides would refuse to engage in the trade activities.

The model of absolute advantage has been illustrated by numeric example in the Table 1 with the simple assumption of the world of two countries and two products. Obviously, this assumption is acceptable because it is considered that in the world there is a Nation and the rest of the world may be as the other Nation. In the below example, the unit of measurement for the productivity in production of product is presented in the number of products per unit.

Table 1: Illustration for absolute advantage

\begin{tabular}{|c|c|c|}
\hline & Nation 1 & Nation 2 \\
\hline Product X & 6 & 5 \\
\hline Product Y & 4 & 1 \\
\hline
\end{tabular}


From the numeric example, it is seen that the Nation 1 has the absolute advantage over the Nation 2 in production of product $\mathrm{X}$ and the Nation 2 has the absolute advantage over the Nation 1 in production of product $\mathrm{Y}$. Both Nations should specialize on production of their products of absolute advantage then export them to other and take the gain from trade. The case of absolute advantage can be illustrated in Figure 1.

Figure 1: Constant alternative costs by geometry

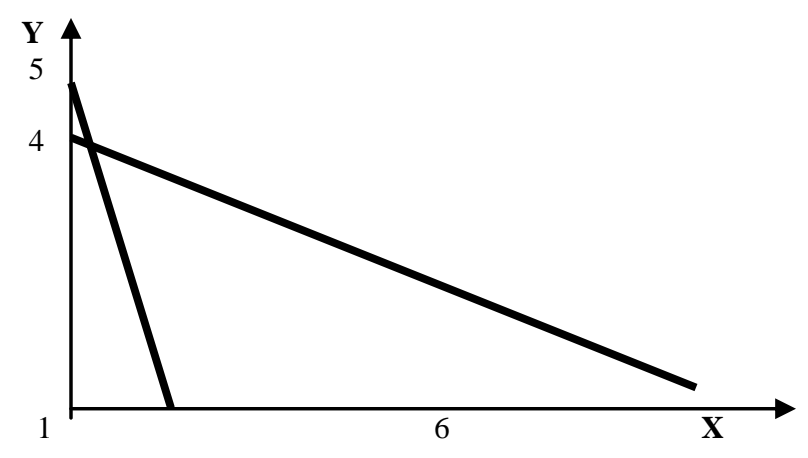

Both straight lines in the graph show the constant alternative costs of the production of their products. These straight lines are intersected. The intersected point of both lines in the first quadrant shows the situation of having the absolute advantage of the Nation.

The explanation about absolute advantage was evaluated as the imperfect view on the international trade when attempting to make clear about the basic for trade, pattern of trade and gain from trade. The imperfect point of theory of absolute advantage levied in the case that a nation had not any absolute advantage in production of all its products. If the nation lied in this situation it is difficult to determine what would be exported and what would be imported in the world of absolute advantage. Departed from this point, the theory on comparative advantage has been developed. D. Ricardo was the representative for this school. The theory of comparative advantage said that in case a Nation has disadvantages in production of all products in comparison with the rest of the world, it would still have the opportunity to gain from trade if such a Nation would specialize on the production of the product of having better relative efficiency than other and vice verse.

The model of comparative advantage has been illustrated by numeric example in Table 2 with the same assumption of the theory of absolute advantage and other assumptions such as the fixed technology, free trade without tariffs, and immobility of labor across nations...

Table 2: Illustration of comparative advantage

\begin{tabular}{|c|c|c|}
\hline & Nation 1 & Nation 2 \\
\hline Product X & 6 & 1 \\
\hline Product Y & 4 & 2 \\
\hline
\end{tabular}

By comparison of the relative productivity of labor between nations, it is seen that the Nation 1 has the comparative advantage over the Nation 2 in production of product $X$ and Nation 2 has comparative advantage over the Nation 1 in production of product $\mathrm{Y}(2 / 4<1 / 6)$ although Nation 2 has absolute disadvantage in production of both products. 
By geometry, the situation of both nations by using the lines of constant alternative costs can be illustrated in the Figure 2. It is obviously recognized that both straight lines of alternative costs of both Nations have not intersected in the graph. However, they have not been still in the parallel. That means they certainly have hidden intersection point in somewhere out of the area presented in Figure 2.

Figure 2: Constant alternative costs by geometry

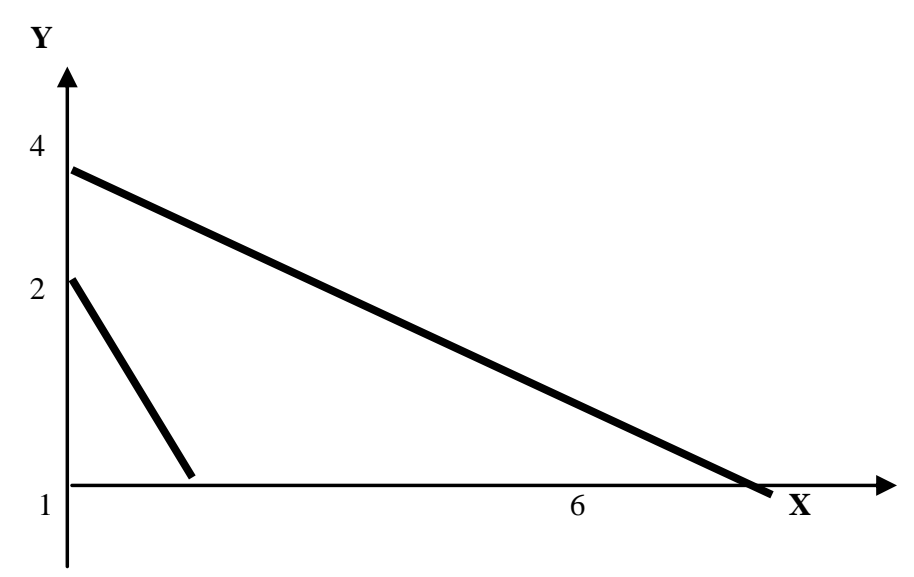

From the graph, it is seen that both lines are not intersected although they are not in the parallel. According to the view of comparative advantage the absolute advantage has been considered as the special case of the comparative advantage. However, it is seen that both lines will be intersected at latent point somewhere. If the space of trade would be expanded, the point of intersection of two lines of alternative cost of both Nations the comparative advantage would become the absolute advantage. It is illustrated in the below figure 3 .

By formulating the equations to present the straight lines of the alternative cost of production of the products in both Nations, the point of intersection of two lines is determined clearly.

For the Nation 1, the equation is: $-3 \mathrm{Y}-2 \mathrm{X}+12=0$ and for the Nation 2 , the equation is: $-\mathrm{Y}-2 \mathrm{X}+2=0$

Based on these equations, the lines of alternative costs will be lengthened to intersect to each other. The equilibrium of both lines of alternative cost of 2 Nations is at the point $E(-1.5,5)$ in the second quadrant in the Figure 3. However, the economic meaning of the alternative cost does not accept the minus sign or the negative value. Therefore, the leftwards shift of the system of axis is necessary to make all the values of the variables positive in economic aspect.

With the assumption of numeric example in the Figure3 and the vertical axis Y moves to the rightwards the new position $\mathrm{Y}^{\prime}$ the result of the new position of the trading Nations in condition of constant alternative cost is illustrated in the Table 3. By such a movement and change of the values, all values related to the alternative costs in new position convey the positive sign.

Table 3: Illustration of new absolute advantage of the comparative advantage

\begin{tabular}{|c|c|c|}
\hline & Nation 1 & Nation 2 \\
\hline Product X & 9 & 4 \\
\hline Product Y & 6 & 8 \\
\hline
\end{tabular}


Figure 3: Illustration of the latent absolute advantage of the comparative advantage by constant alternative costs

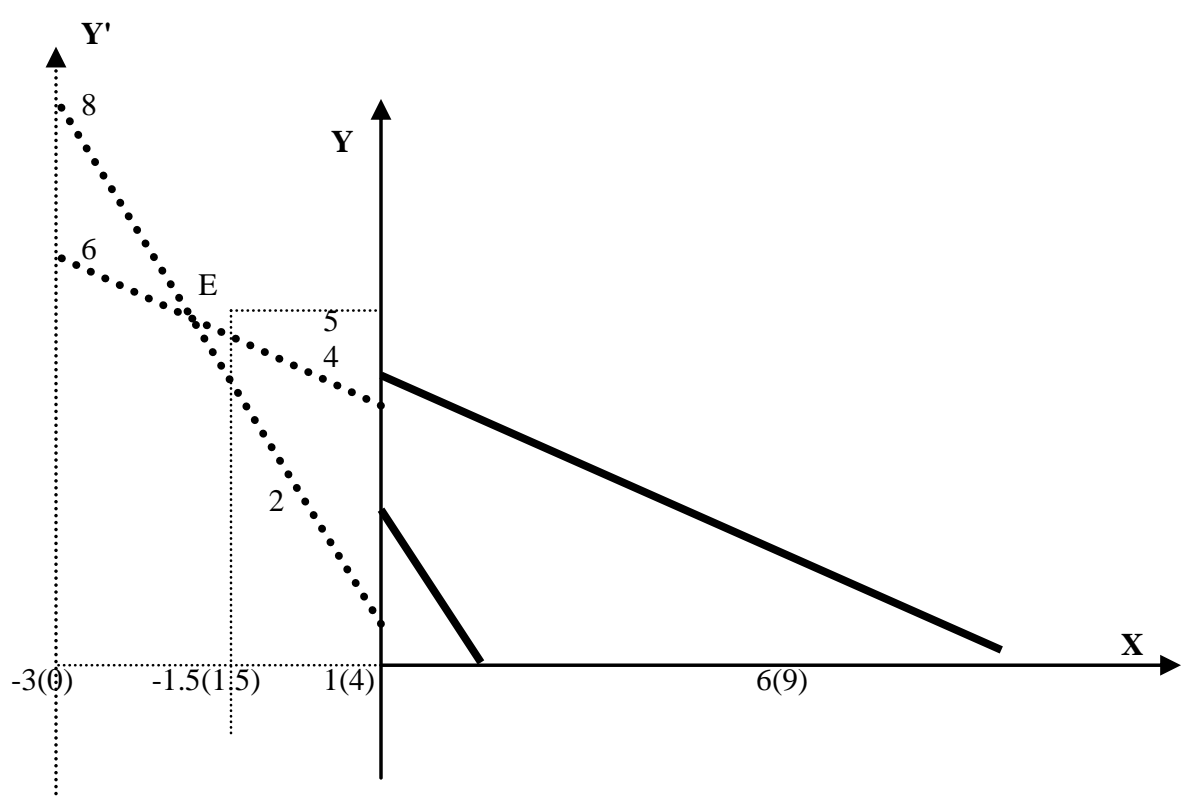

From the numeric example in Table 3, it is clearly recognized that the comparative advantage is transformed to absolute advantage. In Table 2 Nation 2 has disadvantage over both two products but now it has absolute advantage in production of product Y. Here the constant alternative cost has been chosen to simplify the proof and illustration.

Based on the proof by the geometry the conclusion can be taken as follows: the absolute advantage constructs the nature of the comparative advantage. It is conclusion has been in line with the conclusion of Heckscher- Ohlin about the comparative advantage: the relative difference of the factor endowment among countries is the reason of the relative difference of the factor price. Such a difference of factor price leads to the relative difference of the commodity price and from it, the absolute advantage of the commodity price among countries is the direct reason of the trade. That means the relative difference of the price is the intermediate step to the absolute difference of price. In other word, the relative difference of price is the appearance of the absolute difference on it or the comparative advantage has its own latent absolute advantage. It should correctly understand the conclusion of D. Salvatore about absolute advantage in his textbook in adverse meaning. Moreover, it is the sequence of the explanation about this argument by numeric example that shows the asymmetry between the conclusion and the nature of the issue. Perhaps, the forever law of both material world and spiritual world is the approach of all things and thoughts from relative equilibrium towards the absolute equilibrium not vice verse.

\section{REFERENCES}

Binh, D.D. and Lang, N.T. (2002), International Economics, Publishing House of Labor and Society.

Krugman, P. (2001), International Economics.

Salvatore. D. (1998), International Economics (Sixth Edition), page 30.

Smith, A. (1776), The Wealth of Nations 